Введение. Рентгенологическое исследование желудочно-кишечного тракта с контрастированием доступный и информативный метод исследования. Побочные эффректы встречаются крайне редко.

Цель исследования - представить описание случая эмболии воротной вены и печени барием с летальным исходом и объяснить механизм ее возникновения.

Материал и методы. Проанализированы клинические проявления, результаты лабораторных и инструментальных исследований, а также аутопсии пациентки, погибшей после контрастной рентгенографии кишечника.

Результаты. Для исключения кишечной непроходимости пациентке осуществили пассаж бария. Спустя трое суток при рентгеновской компьютерной томографии в нижней брыжеечной вене, воротной вене и ее внутрипечёночных ветвях обнаружен барий и газ. При колоноскопии выявлены дивертикулы сигмовидной кишки, но локализацию кишечно-венозного свища установить не удалось. Проводилась консервативная терапия, которая оказалась безуспешной и спустя 15 суток после контрастной рентгенографрии наступила смерть.

Выводы. При аутопсии установлено, что входными воротами для развития эмболии барием, а также газом, стали аррозированные вены в перидивертикулярных абсцессах, локализовавшихся в периколической клетчатке.

Ключевые слова: барий, эмболия, воротная вена, печень.

\title{
PORTAL VEIN AND LIVER BARIUM EMBOLISM
} ${ }^{1}$ N. I. Prokopchik, ${ }^{1}$ R. E. Yakubtsevich, ${ }^{3}$ S. SH. Kerimova, ${ }^{2}$ A. A Balla, ${ }^{3}$ E. L. Cherevan, ${ }^{2}$ N. V. Belyavsky, ${ }^{3}$ S. N. Drutko, ${ }^{2}$ E. T. Volkova, ${ }^{2}$ N. L. Gavina ${ }^{1}$ Grodno State Medical University, Grodno, Belarus

${ }^{2}$ Grodno University Clinic, Grodno, Belarus ${ }^{3}$ Grodno Regional Clinical and Pathological Bureau, Grodno, Belarus

Background. An upper and lower gastrointestinal (GI) series is an available and informative diagnostic test. Side effects are extremely rare.

Objective. To present a case description of portal vein and liver barium embolism with a fatal outcome and explain the mechanism of its occurrence.

Material and methods. The clinical manifestations, laboratory and instrumental findings, as well as autopsy of a female patient who died after lower GI radiography were analyzed.

Results. To exclude intestinal obstruction, the patient underwent a barium follow through. Three days later, during $X$-ray computed tomography, barium and gas were detected in the inferior mesenteric vein, portal vein and its intrahepatic branches. During colonoscopy, diverticula of the sigmoid colon were detected, but the localization of the intestinalvenous fistula wasn't determined. Conservative surgery failed and the death occurred 15 days after radiography.

Conclusions. The autopsy revealed that the site of entry for the development of barium embolism as well as for gas, were diabrotic veins in peridiverticular abscesses localized in pericolic tissue.

Keywords: barium, embolism, portal vein, liver.

Автор, ответственный за переписку:

Прокопчик Николай Иванович, канд. мед. наук, доц.; Гродненский государственный медицинский университет; e-mail: prokopni@mail.ru

Для цитирования: Эмболия барием воротной вены и печени / Н. И. Прокопчик, Р. Э. Якубцевич, С. Ш. Керимова, А. А. Балла, Е. Л. Черевань, Н. В. Белявский, С. Н. Друтько, Е. Т. Волкова, Н. Л. Гавина // Гепатология и гастроэнтерология. 2021. Т. 5, № 2. С. 191-196. https://doi.org/10.25298/26165546-2021-5-2-191-196
Corresponding author:

Prokopchik Nikolaj, PhD (Medicine), Associate Professor, Grodno State Medical University; e-mail: prokopni@mail.ru

For citation: Prokopchik NI, Yakubtsevich RE, Kerimova SH, Balla AA, Cherevan EL, Belyavsky NV, Drutko SN, Volkova ET, Gavina NL. Portal vein and liver embolism with barium. Hepatology and Gastroenterology. 2021;5(2):191-196. https://doi.org/10.25298/2616-5546-2021-5-2-191-196 


\section{Введение}

Рентгенологическое исследование желудочно-кишечного тракта с контрастированием остается относительно безопасной процедурой. Одно из широко применяемых контрастных веществ - суспензия сульфрата бария - «баритовая каша» с содержанием бария $58,7 \%$.

Пероральный сульфат бария теоретически не токсичен, но имеет противопоказания в использовании, в первую очередь, при нарушениях целостности слизистой оболочки желудочно-кишечного тракта разного происхождения. При таких изменениях возрастают риски развития осложнений: перфораций толстой кишки, венозной эмболизации барием, бариевой гранулемы, баролита, бариевого аппендицита и перитонита [1].

Считается, что H. L. Beddoe и соавт. в 1954 г. впервые сообщили о возникновении осложнений в прямой кишке, обусловленных применением бария [2]. В зарубежной литературе описано не менее 36 случаев попадания бария в кровоток при исследования х желудочно-кишечного тракта со смертельным исходом в 48\% случаев [3]. Эмболия развивалась на фоне неспецифического язвенного колита, болезни Крона, дивертикулита, кишечной непроходимости, рака кишки [1]. В отечественной литературе нам не удалось найти описания такого осложнения.

Важным фактором, влияющим на исход данного осложнения, выступает локализация интравазации бария. У пациентов с дефектами слизистой оболочки тонкой и большей части толстой кишок интравазация происходит через брыжеечные вены в воротную вену, а прямой кишки - через геморроидальные вены в системный кровоток, а затем в лёгкие. Вместе с барием в кровь поступают кишечные бактерии, что сопровождается выделением в кровоток эндотоксинов с последующей активацией калликреин-кининовой системы. Барий активирует выработку брадикинина, что вызывает дрожь, лихорадку, гипотонию, шок, а также диссеминированное внутрисосудистое свертывание крови, способствует в дальнейшем развитию сепсиса [4]. Когда барий попадает в портальный кровоток, печень действует как своеобразный фильтр. Вероятно, это связано с тем, что печёночные ретикулоэндотелиальные клетки поглощают часть бария и уменьшают его поступление в системный кровоток, защищая в какой-то степени от лёгочной эмболии, что объясняет более высокую выживаемость пациентов в этих случаях [1].

Цель исследования - представить описание случая эмболии воротной вены и печени барием с летальным исходом, возникшей при контрастной рентгенографрии кишечника с пассажем бария и объяснить механизм ее возникновения.

\section{Материал и методы}

Проанализированы клинические проявления, результаты лабораторных и инструментальных исследований, а также данные аутопсии пациентки, погибшей вследствие осложнений эмболии воротной вены и печени барием. Объектом для гистологического исследования были кусочки внутренних органов умершей пациентки. Они фриксировались $10 \%$ раствором фрормалина, после проводки заливались в парафин. Гистологические срезы окрашивали гематоксилином и эозином, по Массону, а также на гемосидерин по Перлсу.

\section{Результаты и обсуждение}

Пациентка Ч., 65 лет, была доставлена бригадой скорой медицинской помощи в районную больницу с жалобами на интенсивные боли в животе и многократную рвоту. За сутки до этого, со слов пациентки, появился озноб, повысилась температура тела до $40^{\circ} \mathrm{C}$. В приемном отделении пациентке выполнены общий и биохимический анализы крови, УЗИ органов брюшной полости, рентгенографрия органов грудной клетки. Выявлены лейкоцитоз $(12,7 \times 109 / л$, палочкоядерные нейтрофилы - 14\%, сегментоядерные $78 \%$ ) и увеличение С-реактивного белка (24 мг/л). Признаков острой хирургической патологии не выявлено. Пациентка была госпитализирована в отделение терапии с диагнозом «острая респираторная инфекция», назначена соответствующая терапия. В течение последующих 8 суток состояние пациентки постепенно ухудшалось. Сохранялись жалобы на выраженные боли в животе, повышение температуры тела, появились жалобы на вздутие живота, сухость во рту, общую слабость, гипотонию. На девятые сутки от момента госпитализации пациентка в тяжелом состоянии переведена в отделение реанимации. Артериальное давление 105/70 мм рт. ст., частота сердечных сокращений 96 в 1 минуту. Температура $37,5^{\circ} \mathrm{C}$. Живот вздут, при пальпации умеренно болезненный в эпигастральной области. Перистальтика кишечника сохранена, симптомы раздражения брюшины отсутствуют. После осмотра хирургом, для исключения кишечной непроходимости, пациентке выполнен пассаж бария под контролем рентгенографии. Через 21 час барий определился в прямой кишке, каких-либо дефектов наполнения не выявлено. При УЗИ в печени обнаружено кистоподобное образование до 17 мм в диаметре, что расценено как абсцесс печени. Через двое суток при УЗИ в печени обнаружены множественные гиперэхогенные очаги и анэхогенное образование до 12 мм в диаметре. При КТ структура печени крайне неоднородна за счет неправильной формы гиперденсивных участков в паренхиме, распространяющихся 
вдоль воротной вены. В ветвях v. portae в правой доле печени, тотально их заполняя, определяется контрастное средство плотностью +1600 $+1800 \mathrm{HU}$ (бариевый контраст). В воротной вене и нижней брыжеечной вене также определяется контрастное средство, расположенное пристеночно. Кроме того, в ветвях воротной вены левой доли печени и в брыжеечной вене обнаружен газ. Выявленные изменения расценены как следствие наличия фистулы между кишечником и сосудистым руслом, однако визуализировать местонахождение соустья не удалось. На следующие сутки отмечено нарастание уровня палочкоядерных нейтрофилов (41\%), тромбоцитопении (27×109/л), СОЭ (21 мм/ч), С-реактивного белка (156 мг/л), АсАТ (424 ед/л), АЛТ (81,0 ед/л) и прокальцитонина (13,27 нг/мл). Выполнен посев крови на стерильность, получен рост грамположительных кокков. На основании полученных данных выставлен диагноз «Пилефлебит. Аэробилия? Свищ системы воротной вены? Холангит. Криптогенный сепсис?» и пациентка переведена в отделение реанимации Гродненской университетской клиники.

В отделении реанимации продолжена антибактериальная терапия (меропенем 2,0 в/в ч/3 8 ч и линезолид 600 мг в/в ч/з 12 ч). Из крови выделен Enterococcus faecalis. На КТ подтверждено наличие гиперденсивных множественных участков уплотнения прежних размеров. В просвете видимых отделов нижней брыжеечной вены содержится контрастный препарат (по типу бариевой взвеси), с пузырьками газа на его фоне, причем контрастный препарат и пузырьки газа распространяются краниально в просвет воротной вены, а также в просветы ее правой и левой ветвей, просветы сегментарных и более мелких ветвей (рис. 1). Следы аналогичного по плотности контрастного препарата прослеживаются в просвете видимых отделов поперечноободочной кишки, а также сигмовидной и прямой

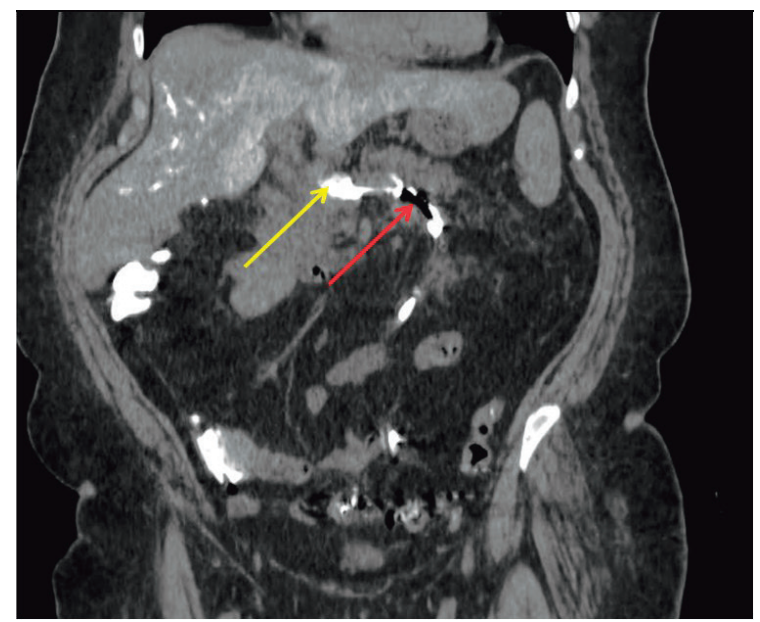

Рисунок 1. - КТ-изображение в корональной ной вене (желтая стрелка); пузырьки газа в нижней брыжеечной вене (красная стрелка) Figure 1. - CT image in the coronal plane: contrast agent in the portal vein (yellow arrow); gas bubbles in the inferior mesenteric vein (red arrow) кишок. На шестые сутки после контрастной рентгенографрии кишечника у пациентки развилась остановка сердечной деятельности на фоне выраженной дыхательной недостаточности. Через 20 минут ритм был восстановлен, пациентка переведена на искусственную вентиляцию лёгких. На следующие сутки с целью уточнения диагноза и попытки локализации кишечно-венозного свища была выполнена колоноскопия, во время которой обнаружены множественные дивертикулы сигмовидной кишки диаметром до 0,5 см, многие из которых были заполнены каловыми камнями. Лабораторно: лейкоцитоз (27,2×109/л), нарастание уровня мочевины (19 ммоль/л), креатинина (269 мкмоль/л), сохраняются повылиум и выставлен диагноз «Пилефлебит. Аэробилия. Свищ системы воротной вены? Холангит. Сепсис. СПОН». Ввиду отсутствия возможности установить четкую локализацию соустья между кишечником и воротной веной, решено продолжить консервативную терапию. На 10-е сутки выполнено повторное КТ, по результатам которого выявлено увеличение объема газа в печени, усиление неоднородности паренхимы печени за счет увеличения количества гиподенсивных участков. На 27-е сутки от начала заболевания и на 18-е сутки после пассажа бария у пациентки повторно возникла остановка сердечной деятельности. Реанимационные мероприятия оказались безуспешными.

При аутопсии в левом боковом канале брюшной полости и малом тазу обнаружены множественные спайки. В сигмовидной кишке и проксимальном отделе прямой кишки выявлены множественные дивертикулы, диаметром от 1,0 до 3,0 см. На границе сигмовидной и прямой кишки, в утолщенной до 2,5-3,0 см периколической клетчатке определялись кистозные полости диаметром от 1,0 см до 1,8 см, неправильной формы с грязно-кровянисто-бурым полужидким содержи-

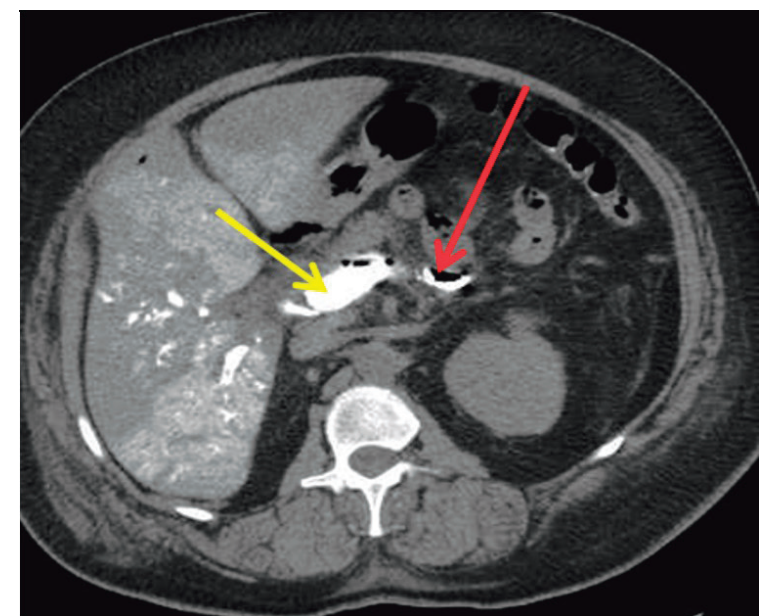

плоскости: контрастное вещество в воротшенные уровни АсАТ и АлАТ. Проведен конси- 
мым (абсцессы). Некоторые из них сообщались с просветом толстой кишки нечетко контурирующимися свищевыми ходами. Печень массой 2400 г дряблой консистенции. Капсула ее гладкая, блестящая, на разрезе ткань печени темно-багрового цвета с множественными участками более бледного цвета. Воротная вена диаметром до 11 мм, в ее просвете содержалась жидкая кровь.

При гистологическом исследовании толстой кишки (вне дивертикулов) в слизистой оболочке отмечались гиперсекреция слизи, десквамация эпителия, множественные эрозии и кристаллы бария. В дивертикулах стенка кишки была представлена слизистой и подслизистой оболочками, мышечная оболочка отсутствовала или состояла из одного слоя мышечных волокон, с обилием толстостенных, расширенных сосудов венозного типа. В брыжейке, по периферии дивертикулов, определялись абсцессы с наличием в полостях гноя, свертков крови и кристаллов сульфата бария (рис. 2). В стенке абсцессов обнаружен флебит с очагом деструкции стенки вен и с наличием в просвете вены кристаллов бария (рис. 3).

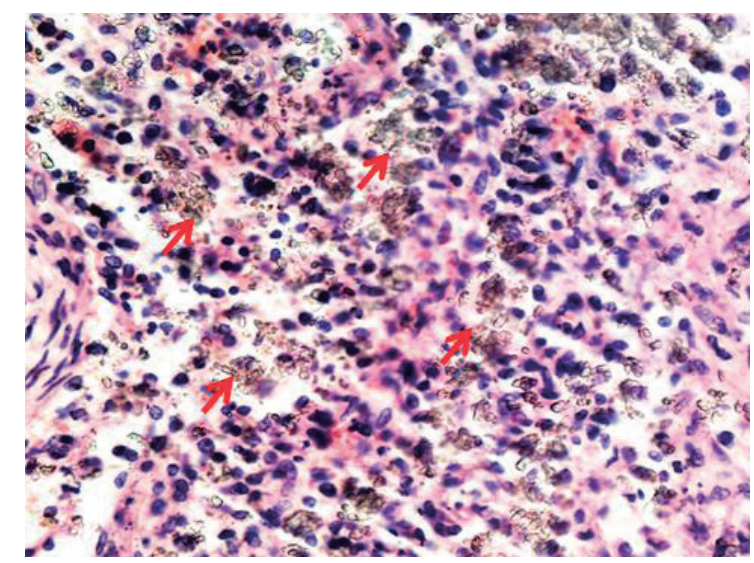

Рисунок 2. - Абсцесс периколической клетчатки: среди гнойного экссудата определяются полупрозрачные кристаллы сульфата бария (стрелкu). Окр.: гематоксилином и эозином. $\quad \times 200$ Figure 2. - Abscess of pericolic fiber: translucent crystals of barium sulfate are detected among purulent exudate (arrows). Coloring: hematoxylin and eosin. $\times 200$

Патогистологическое исследование печени: междольковые артерии и желчные протоки обычного строения; некоторые субсегментарные и междольковые вены расширены, заполнены фрибрином с примесью кристаллов сульфата бария, с воспалительными изменениями и наличием в клеточном инфильтрате большого количества гигантских многоядерных клеток типа инородных тел, осуществляющих фрагоцитоз бария (рис. 4, 5).

Местами в печени обнаружены абсцессы, которые локализовались в портальных трактах и распространялись на перипортальные зоны (рис. 6).

Кристаллы бария определяются также в синусоидах, преимущественно 1 зоны долек, а также

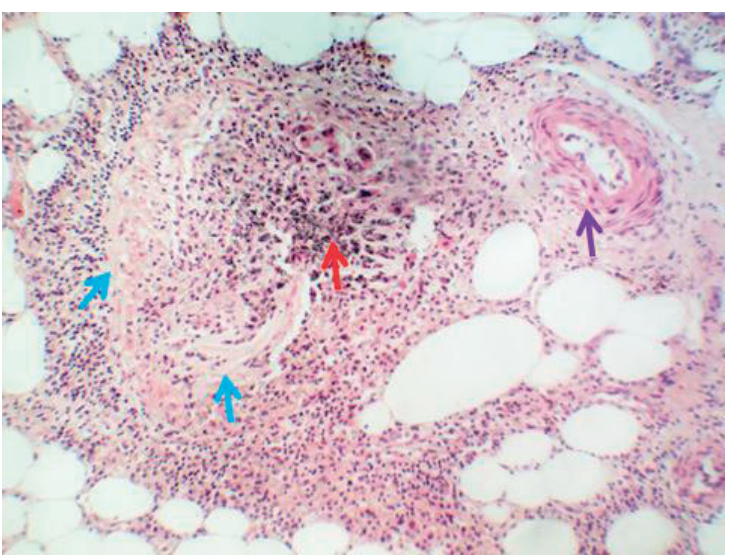

Рисунок 3. - Флебит с деструкцией вены в стенке абсцесса периколической клетчатки: стенка вены (синие стрелки) на большем протяжении некротизирована, с наличием воспалительного инфильтрата с большим количеством гигантских многоядерных клеток типа инородных тел и кристаллов бария (красная стрелка); артерия без признаков воспаления (сиреневая стрелка). Окр.: гематоксилином и эозином. ×100 Figure 3. - Phlebitis with destruction of a vein in the wall of a pericolic fiber abscess: the vein wall (blue arrows) is necrotized for a longer period with the presence of an inflammatory infiltrate with a large number of giant multinucleated cells such as foreign bodies and barium crystals (red arrow); an artery without signs of inflammation (lilac arrow). Coloring: hematoxylin and eosin. $\times 100$

в зоне центролобулярных некрозов (рис. 7, 8). Последние локализовались в печени повсеместно, имели разную давность происхождения. Некрозам предшествовала жировая дистрофия с исходом в некробиоз. В очагах резорбции тканевого детрита синусоиды были резко расширены, переполнены кровью. Целостность центральных вен сохранена.

Таким образом, в результате патологоанатомического исследования установлено, что входными воротами для развития эмболии сульфатом бария стали аррозированные вены в стенках перидивертикулярных абсцессов, локализовавшихся в периколической клетчатке. Эмболия печени осложнилась множественными центролобулярными некрозами смешанного генеза. Во-первых, они развились вследствие тромбофлебита внутрипечёночных ветвей воротной вены, индуцированного как инородным веществом (барием), а во-вторых - с повышенным поступлением в печень по воротной вене эндотоксинов, вырабатываемых грамотрицательной микрофлорой, колонизирующейся, как известно, преимущественно в дистальных отделах толстой кишки, так и экзотоксинов на фоне сепсиса. Барьерная функция кишечника была нарушена в связи с наличием эрозивного колита и дивертикулита, а аналогичная функция печени - в связи с возникшим тромбофлебитом внутрипечёночных ветвей воротной вены и гипоксией [5]. В литературе указывается, что причиной центролобулярных некрозов печени может также стать таниновая кислота, которая может входить в состав суспензий для улучшения адгезии бария к поверхности слизистой оболочки кишки и улучшения визуали- 


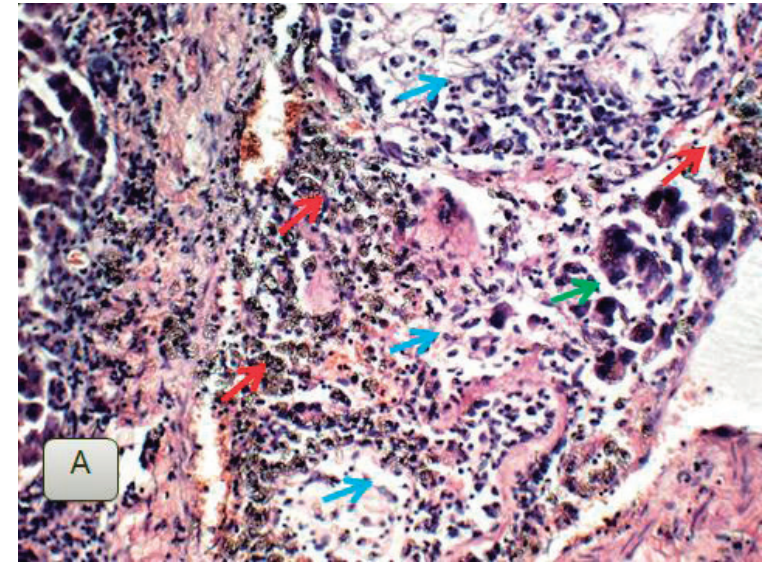

Рисунок 4 лов бария и гигантских многоядерных клеток типа инородных тел с фагоцитированным барием (барий - красные стрелки; фибрин с лейкоцитарной инфильтрацией - синие стрелки; гигантские многоядерные клетки типа инородных тел - зеленые стрелки). Окр.: гематоксилином и эозином. × 200 (a), ×400 (б) Figure 4. - Thrombophlebitis of a subsegmental vein with the presence in the lumen of a thrombus, barium crystals and giant multinucleated cells of the type of foreign bodies with phagocytized barium (barium - red arrows; fibrin with leukocyte infiltration - blue arrows; giant multinucleated cells of the type of foreign bodies - green arrows). Coloring: hematoxylin and eosin. $\times 200$ (a), $\times 400$ (b)

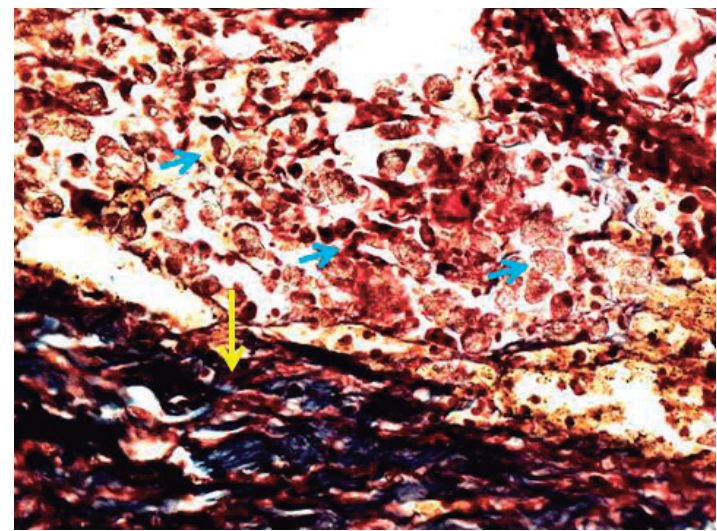

Рисунок 5. - Флеботромбоз субсегментарной вены: в вене определяется тромб с кристаллами бария (синие стрелки); стенка вены - желтая стрелка. Окр.: по Массону. х400 Figure 5. - Phlebothrombosis of the subsegmental vein: a blood clot with barium crystals is detected in the vein (blue arrows); the vein wall is a yellow arrow. Coloring: according to Masson. $\times 400$

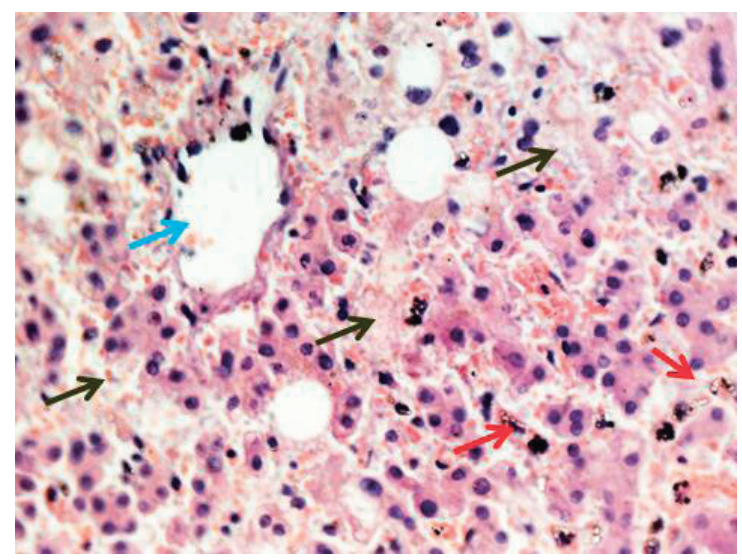

Рисунок 7. - Резко выраженная дистросии, некробиоз и очаговый некроз гепатоцитов 3 зоны печёночной дольки: синяя стрелка - центральная вена, черные стрелки - некробиоз и некроз гепатоцитов, красные стрелки-кристаллы бария. Окр.: гематоксилином и эозином. х400 Figure 7. - Pronounced dystrophy, necrobiosis and focal necrosis of hepatocytes 3 zones of the hepatic lobule: blue arrow - central vein, black arrows - necrobiosis and necrosis of hepatocytes, red arrows - barium crystals. Coloring: hematoxylin and eosin. $\times 400$

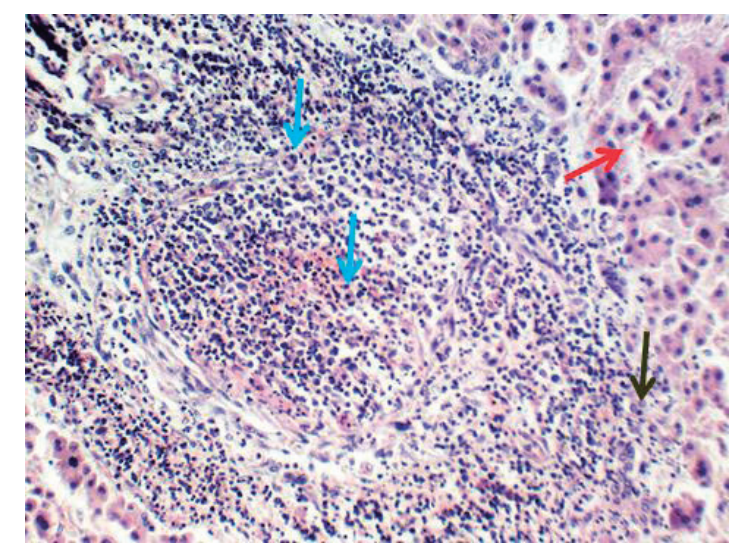

Рисунок 6. - Абсцесс печени: в портальном тракте и перипортально ограниченное гнойное воспаление с образованием полости, заполненной гноем (абсцесс - синие стрелки; пограничная пластинка разрушена за счет воспаления - черная стрелка; ткань печени - красная стрелка). Окр.: гематоксилином и эозином. ×200 Figure 6. - Liver abscess: limited purulent inflammation is detected in the portal tract and periportally with the formation of a cavity filled with pus (abscess - blue arrows; border plate destroyed due to inflammation - black arrow; liver tissue - red arrow). Coloring: hematoxylin and eosin. $\times 200$

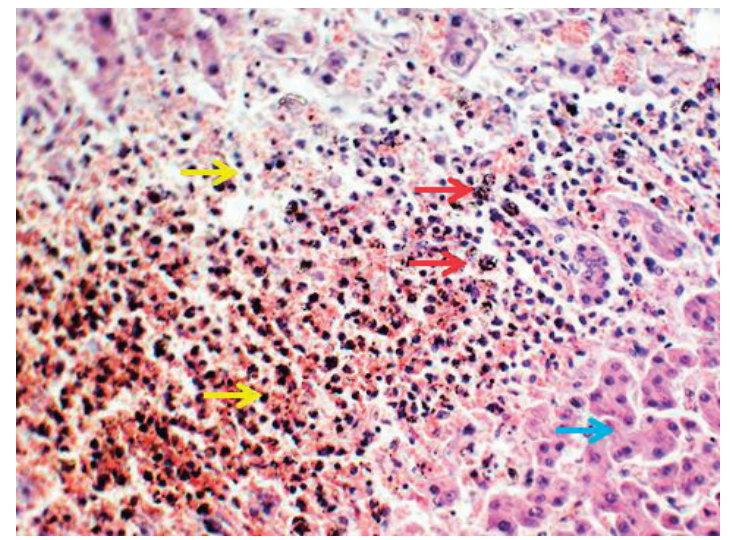

Рисунок 8. - Центролобулярный некроз: детрит подвергся резорбции, синусоиды расширены и переполнены кровью (желтые стрелки); кристаллы бария (красные стрелки); сохранившаяся ткань печени (синяя стрелка). Окр.: гематоксилином и эозином. ×200 Figure 8. - Centrolobular necrosis: detritus has undergone resorption, sinusoids are dilated and overflowing with blood (yellow arrows); barium crystals (red arrows); preserved liver tissue (blue arrow). Coloring: hematoxylin and eosin. $\times 200$ 
зации изменений в кишечнике [6]. В описанном нами случаи использовался препарат марки “БарВИПС", который танин не содержит.

Выявленный при КТ-исследовании газ в воротной и брыжеечной венах был результатом попадания из кишечника внутрипросветного газа через эрозированную слизистую толстой кишки и через аррозированные сосуды в перидивертикулярных абсцессах. Общеизвестно, что воспалительные процессы в кишечнике сопровождаются как повышенным газообразованием, так и замедлением транспортировки конечных катаболических продуктов микроорганизмов [7]. К наиболее частым газообразующим патогенам относится и Klebsiella pneumoniae, высеянная у пациентки из крови.

\section{Выводы}

Приведенное наблюдение подтверждает, что контрастирование кишечника с помощью сульфата бария имеет противопоказания и может завершиться эмболией барием воротной вены и печени с фатальным исходом. Благодаря доступности КТ и МРТ, эмболия барием легко диагностируется, но, к сожалению, в настоящее время нет специфического лечения возникшего осложнения, а исход такого осложнения непредсказуем.

\section{References}

1. Takahashi M, Fukuda K, Ohkubo Y, Tokuhiro N, Tsuchiya R, Yoshie M, Hirai Y. Nonfatal barium intravasation into the portal venous system during barium enema examination. Intern Med. 2004;43(12):1145-50. doi: 10.2169/internalmedicine.43.1145

2. Beddoe HL, Kay S, Kaye S. Barium granuloma of the rectum; report of a case. J Am Med Assoc. 1954;154(9):747-9. doi: 10.1001/jama.1954.02940430017005a.

3. White JS, Skelly RT, Gardiner KR, Laird J, Regan MC Intravasation of barium sulphate at barium enema examination. $\mathrm{Br} J$ Radiol. 2006;79(943):e32-5. doi: 10.1259/ bjr/57839881.

4. Maceda S, González A, Lado F. Embolia pulmonar por bario [Pulmonary embolism caused by a barium enema]

Конфоликт интересов. Авторы заявляют об отсутствии конфликта интересов.

Финансирование. Исследование проведено без спонсорской поддержки.

Соответствие принципам этики. Исследование одобрено локальным этическим комитетом.

Сведения об авторах:

Прокопчик Николай Иванович, канд. мед. наук, доц. Гродненский государственный медицинский университет; e-mail: prokopni@mail.ru, ORCID: 0000-0001-9319-9896,

Якубцевич Руслан Эдвардович, д-р мед. наук, доц.; Гродненский государственный медицинский университет; e-mail: jackruslan@tut.by; ORCID: 0000-0002-8699-8216

Керимова Сапартач Ширдогдыевна, Гродненское областное клиническое патологоанатомическое бюро; e-mail: kerimowa1993@bk.ru

Балла Александр Александрович, Гродненская университетская клиника; e-mail: alexsanderballa@gmail.com

Черевань Евгений Леонидович, Гродненское областное клиническое патологоанатомическое бюро; e-mail: dr_ cherevan@mail.ru

Белявский Николай Викторович, Гродненская университетская клиника; e-mail: neurogames@gmail.com

Друтько Сергей Николаевич, Гродненское областное клиническое патологоанатомическое бюро; e-mail: patanatom@ list.ru

Волкова Екатерина Тадеушевна, Гродненская университетская клиника; e-mail: miss.ptychk@mail.ru

Гавина Наталья Львовна, Гродненская университетская клиника; e-mail: n.I.gavina@yandex.by
Arch Bronconeumol. 2003;39(11):532-3. doi: 10.1016/ s0300-2896(03)75447-7. (Spanish).

5. Han DW. Intestinal endotoxemia as a pathogenetic mechanism in liver failure. World J Gastroenterol. 2002;8(6):9615. doi: 10.3748/wjg.v8.i6.961.

6. Rambo ON, Zboralske FF, Harris PA, Riegelman S, Margulis AR. Toxicity studies on tannic acid administered by enema. I. Effects of enema-administered tannic acid on the colon and liver of rats. Am J Roentgenol Radium Ther Nucl Med. 1966;96(2):488-97. doi: 10.2214/ajr.96.2.488.

7. Shah PA, Cunningham SC, Morgan TA, Daly BD. Hepatic gas: widening spectrum of causes detected at CT and US in the interventional era. Radiographics. 2011;31(5):1403-13. doi: $10.1148 / \mathrm{rg} .315095108$

Conflict of interests. The authors declare no conflict of interests.

Financing. The study was perfomed without external funding

Conformity with principles of ethics. The study was approved by the local ethics committee.

Information about the authors:

Prokopchik Nikolaj, PhD (Medicine), Associate Professor, Grodno State Medical University, e-mail: prokopni@mail.ru, ORCID: 0000-0001-9319-9896

Yakubtsevich Ruslan, PhD, MD (Medicine), Associate Professor, Grodno State Medical University, e-mail: jackruslan@ tut.by; ORCID: 0000-0002-8699-8216

Kerimova Sapartach, Grodno Regional Clinical and Pathological Bureau, e-mail: kerimowa1993@bk.ru

Balla Aleksandr, Grodno University Clinic, e-mail: alexsanderballa@gmail.com

Cherevan Evgenij, Grodno Regional Clinical and Pathological Bureau, e-mail: dr_cherevan@mail.ru

Belyavsky Nikolaj, Grodno University Clinic, e-mail: neurogames@gmail.com

Drutko Sergej, Grodno Regional Clinical and Pathological Bureau, e-mail: patanatom@list.ru

Volkova Ekaterina, Grodno University Clinic, e-mail: miss. ptychk@mail.ru

Gavina Natal'ya, Grodno University Clinic, e-mail:n.I.gavina@ yandex.by
Поступила: 21.10.2021

Принята к печати: 27.10.2021
Received: 21.10.2021

Accepted: 27.10.2021 